\title{
Atmospheric emissions from road transportation in India
}

\author{
S. Baidya ${ }^{\mathrm{a}, *}$, J. Borken-Kleefeld ${ }^{\mathrm{a}, \mathrm{b}}$ \\ ${ }^{a}$ German Aerospace Centre (DLR), Transportation Studies, Rutherfordstrasse 2, 12489 Berlin, Germany \\ ${ }^{\mathrm{b}}$ International Institute for Applied Systems Analysis (IIASA), 2361 Laxenburg, Austria
}

\section{A R T I C L E I N F O}

\section{Article history:}

Received 27 March 2009

Accepted 15 July 2009

\section{Keywords:}

India

Emission inventory

Uncertainty

\begin{abstract}
A B S T R A C T
India has become one of the biggest emitters of atmospheric pollutants from the road transportation sector globally. Here we present an up-to-date inventory of the exhaust emissions of ten species. This inventory has been calculated bottom-up from the vehicle mileage, differentiating by seven vehicle categories, four age/technology layers and three fuel types each, for the seven biggest cities as well as for the whole nation. The age composition of the rolling fleet has been carefully modelled, deducting about one quarter of vehicles still registered but actually out-of-service. The vehicle mileage is calibrated to the national fuel consumption which is essential to limit uncertainties. Sensitivity analyses reveal the primary impact of the emission factors and the secondary influence of vehicle mileage and stock composition on total emissions. Emission estimates since 1980 are reviewed and qualified. A more comprehensive inspection and maintenance is essential to limit pollutant emissions; this must properly include commercial vehicles. They are also the most important vehicle category to address when fuel consumption and $\mathrm{CO}_{2}$ emissions shall be contained.
\end{abstract}

(c) 2009 Elsevier Ltd. All rights reserved.

\section{Emissions from road transportation in India rising}

Emission inventories provide essential input data for modelling the atmospheric composition and subsequent impacts e.g. in terms of air pollution and radiative forcing. Particularly uncertain are emissions from countries in transition, for instance from India. This country has the second largest populations of the world and its gross domestic product has almost doubled between 1995 and 2005 (IMF, 2008). In the same period, the sales of motorised two wheelers and cars have almost tripled (SIAM, 2006 and 2008). This strong motorization has caused increasing concerns about local and long-range air pollution, its impacts on climate change and on the global demand for oil. Indeed, already by the year 2000, India was among the ten countries with highest exhaust pollutants from the road transportation sector (Borken et al., 2007) and road fuel consumption approximately doubled every ten years since 1980 .

Due to this rapid growth and the related technological changes previous emission inventories quickly outdate. Here we present a comprehensive emission inventory for road transportation in India in the year 2005. It is based on a thorough review of available data, own literature and field research, and interviews with Indian experts. We construct a consistent data base for the running vehicle fleet, their average annual mileage, fuel efficien-

\footnotetext{
* Corresponding author. Tel.: +977 9849269359; fax: +97711660360.

E-mail addresses: baidya@gmx.de (S. Baidya), borken@iiasa.ac.at (J. Borken-Kleefeld).
}

cies and emission factors; the data is differentiated by 7 vehicle categories, 3 fuel types and 4 age/technology levels for both the seven most populated cities as well as the whole nation. We have treated passenger and freight transport at the same level of detail and hence also included tractors as conventional means of rural transportation. Thus we go substantially beyond current knowledge with a finer differentiation of the vehicle technology, a larger scope of ten pollutants and the regional disaggregation while being consistent and up-to-date. This differentiation is necessary for any informed and quantitatively relevant action. Moreover, our bottom-up calculation serves to delimit uncertainties in regional and global emission inventories, and is necessary for modelling future changes.

\section{Previous emission estimates}

There are a number of estimates for emissions from road transportation in India. Details of reference years, methods and input data of the previous works are presented in Table 1. They take either fuel consumption or vehicle mileage as activity data, i.e. follow either the basic Tier 1 or the more sophisticated Tier 2 approach according to IPCC (1996). Various aspects and discrepancies become apparent in a closer inspection of the emission estimates: Road transport has at least doubled its $\mathrm{CO}_{2}$ emissions from 57 to $70 \mathrm{Tg}$ in 1990 to 134 to $220 \mathrm{Tg}$ in 2005 (Fig. 1a). This growth rate is similar in all emission estimates, but a spread of about $10-20 \mathrm{Tg}$ in calculated $\mathrm{CO}_{2}$ emissions has not 
Table 1

Various estimates of road transport's emissions in India and implied emission factors.

\begin{tabular}{|c|c|c|c|c|c|c|c|c|c|c|c|c|c|}
\hline \multirow[t]{2}{*}{ Reference } & \multirow[t]{2}{*}{ Year } & \multirow[t]{2}{*}{ Group } & \multicolumn{6}{|c|}{ Total estimates, Gg } & \multicolumn{5}{|c|}{ g pollutant per $\mathrm{kg} \mathrm{CO} 2$} \\
\hline & & & $\mathrm{CO}_{2}$ & $\mathrm{CO}$ & $\mathrm{HC}$ & NO & PM & $\mathrm{SO}_{2}$ & $\mathrm{CO}$ & $\mathrm{HC}$ & $\mathrm{NO}_{x}$ & PM & $\mathrm{SO}_{2}$ \\
\hline ADB (2006) & 2005 & 3 & 220,000 & & & & 241 & & & & & 1.1 & \\
\hline This work, Max. & & 3 & 146,854 & 9258 & 2213 & 2545 & 444 & 55 & 63.0 & 15.1 & 17.3 & 3.0 & 0.4 \\
\hline This work, Ref. & & 3 & 146,328 & 4909 & 1625 & 1981 & 274 & 55 & 33.5 & 11.1 & 13.5 & 1.9 & 0.4 \\
\hline Garg et al. (2006) & & 1 & 143,000 & 5350 & & 1696 & 2190 & 85 & 37.4 & & 11.9 & 15.3 & 0.6 \\
\hline Fulton and Eads (2004) & & 2 & 135,384 & 10722 & 2256 & 1665 & 201 & & 79.2 & 16.7 & 12.3 & 1.5 & \\
\hline This work, Min. & & 3 & 133,879 & 3342 & 1187 & 1538 & 200 & 50 & 25.0 & 8.9 & 11.5 & 1.5 & 0.4 \\
\hline This work, with CPCB (2000) & & 3 & 133,879 & 1840 & 812 & 1228 & 143 & 54 & 13.7 & 6.1 & 9.2 & 1.1 & 0.4 \\
\hline IIASA (2008) & & 1 & 133,760 & & & 1260 & 144 & 164 & & & 9.4 & 1.1 & 1.2 \\
\hline Van Aardenne et al. (2005) & 2000 & 1 & 119,818 & 4775 & 1693 & 1324 & & 888 & 39.9 & 14.1 & 11.1 & & 7.4 \\
\hline Garg et al. (2006) & & 1 & 116,000 & 4470 & & 1380 & 2040 & 138 & 38.5 & & 11.9 & 17.6 & 1.2 \\
\hline Singh et al. (2008) & & 1 & 105,000 & 3500 & 712 & 1100 & & & 33.3 & 6.8 & 10.5 & & \\
\hline IIASA (2008) & & 1 & 102,550 & & & 1082 & 122 & 211 & & & 10.5 & 1.2 & 2.1 \\
\hline Borken et al. (2007) & & 2 & 99,594 & 3257 & 1033 & 1317 & 105 & 126 & 32.7 & 10.4 & 13.2 & 1.1 & 1.3 \\
\hline Ohara et al. (2007) & & 1 & 86,379 & 7061 & 2840 & 1451 & & 173 & 81.7 & 32.9 & 16.8 & & 2.0 \\
\hline Mittal and Sharma (2003) & 1997 & 2 & 42,930 & 2163 & 1952 & & 116 & 896 & 50.4 & 45.5 & & 2.7 & 20.9 \\
\hline Olivier et al. (2002) & 1995 & 1 & 98,740 & 3561 & 1227 & 1113 & & 753 & 36.1 & 12.4 & 11.3 & & 7.6 \\
\hline Garg et al. (2006) & & 1 & 89,000 & 3220 & & 985 & 1970 & 243 & 36.2 & & 11.1 & 22.1 & 2.7 \\
\hline IIASA (2008) & & 1 & 78,820 & & & 1015 & 93 & 252 & & & 12.9 & 1.2 & 3.2 \\
\hline Ramanathan and Parikh (1999) & 1994 & 2 & 79,000 & 1769 & 648 & & 33 & & 22.4 & 8.2 & & 0.4 & \\
\hline MiEF (2004) & & 1 & 71,892 & & & & & & & & & & \\
\hline Bhattacharya and Mitra (1998) & & IV & 69,800 & 4107 & 1594 & & & & 58.8 & 22.8 & & & \\
\hline Garg et al. (2006) & 1990 & 1 & 70,000 & 2500 & & 670 & 1690 & 201 & 35.7 & & 9.6 & 24.1 & 2.9 \\
\hline IIASA (2008) & & 1 & 61,670 & & & 861 & 70 & 197 & & & 14.0 & 1.1 & 3.2 \\
\hline Olivier et al. (2002) & & 1 & 60,463 & 2570 & 928 & 658 & & 440 & 42.5 & 15.3 & 10.9 & & 7.3 \\
\hline Bhattacharya and Mitra (1998) & & IV & 57,300 & 3493 & 1371 & & & & 61.0 & 23.9 & & & \\
\hline Singh et al. (2008) & 1980 & 1 & 27,000 & 900 & 203 & 300 & & & 33.3 & 7.5 & 11.1 & & \\
\hline
\end{tabular}

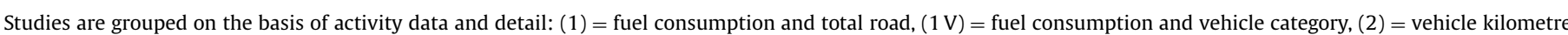
and vehicle category, (3) = vehicle kilometre and vehicle sub category.
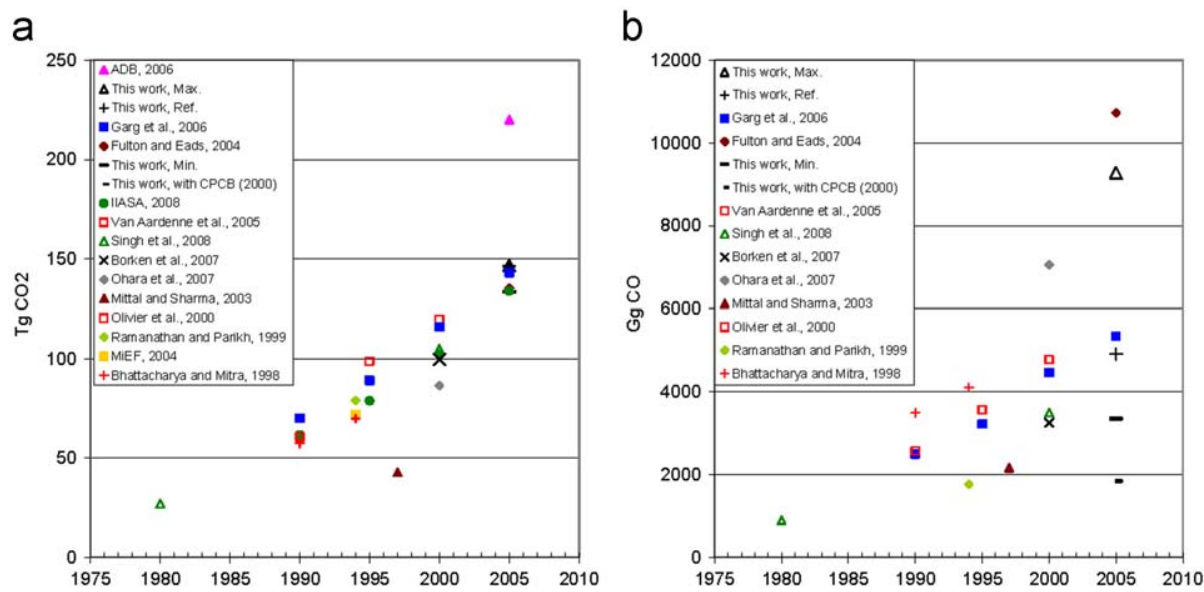

Fig. 1. Exhaust emissions from road transportation in India 1980-2005 according to different author: (a) $\mathrm{CO}_{2}$ emissions; and (b) $\mathrm{CO}$ emissions.

narrowed with time, outliers excluded. Hence the uncertainty about the underlying transport activity, either measured as fuel consumed for road transportation or vehicle mileages has remained. In addition, the emission factors used vary considerably across the different studies; therefore, the resulting non- $\mathrm{CO}_{2}$ emissions have a much larger span. CO emissions, for example, easily differ by a factor of two according to different calculations (Fig. 1b). There is no apparent systematic in the total pollutant emissions from various authors, though they use partly the same emission factors as input data. In part this is due to different assumptions about the share of traffic volume or the fuel respectively by vehicle category. The different calculations only concur that emissions have grown significantly over the past decades. The question is how has been the most recent development and is it possible to narrow down the uncertainties?

\section{Approach}

Indian road vehicles have tremendously diversified in the past decade. There are uncontrolled vehicles all over the country as well as EURO III equivalent cars in the mega cities. Such a variety demands a Tier 2 approach. Furthermore our input data must be differentiated by technology layer for a differentiated analysis. However, a further differentiation as implemented in the authoritative and sophisticated European and North American 
calculation methods (e.g. Ntziachristos and Samaras, 2000; Gkatzoflias et al., 2007; HBEFA, 2004; US-EPA, 2002) is quickly limited by the lack of representative or reliable data for India.

The technology layer in this work includes vehicle category, fuel type, operation (e.g. taxi and private use for passenger cars), engine type (two and four stroke) and emission control technologies. Driving conditions are defined by different road types (urban and rural).

The total emissions $E$ of a pollutant $p$ are calculated with the formula:

$E_{P}=\sum_{g, t}\left\{\left(N_{v, g} \cdot S_{t, g}\right) \cdot K M_{t, g} \cdot \sum_{r}\left(D_{t, r} \cdot e_{t, r, p, g}\right)\right\}$,

where $N$ is the number of circulating vehicles, $S$ the share of sub vehicle category, $K M$ the average annual distance travelled by vehicles in $\mathrm{km}, D_{r}$ the share of the average annual kilometre on road category $r$, and $e$ the emission factor in $\mathrm{g} / \mathrm{km}$. The suffix $v$ stands for the vehicle category, $t$ the vehicle sub category, $g$ the emission concept or age group.

This differentiation brings the emission calculation for Indian road transportation a step closer to the state-of-art modelling in industrialised countries. However a number of sophistications used there are here left out due to lack of data: A differentiation of emission behaviour e.g. by traffic situation or driving mode; a further classification of vehicles by weight or engine size; cold start effects and evaporative emissions.

All factors of the calculation are derived in the following: The rolling fleet, their annual mileage and average emission factors, each in the desired level of detail. Central values are derived based on literature, own research and plausible assumptions. The sensitivity for the results is analysed systematically later.

To group the fleet into layers of relatively homogenous emission behaviour, we use the following seven vehicle categories: Motorized two wheelers (M2W), motorized three wheelers (M3W), passenger cars and taxis (cars), busses and coaches, light duty trucks (LDT, $\leq 3.5$ t GVW), heavy duty trucks (HDT, $>3.5 \mathrm{t}$ GVW), and tractors. Where applicable, each vehicle category is differentiated by up to three fuel types or engine concepts respectively: Spark ignition engines running on gasoline or compressed natural gas (CNG), or compression ignition engines running on diesel and CNG fuels. Motorized two and three wheelers are further differentiated by two stroke and four stroke engine. Each vehicle-fuel type combination is further differentiated by four age groups corresponding to the 5-years brackets of the Indian exhaust emission regulations: Until 1990; 1991-1995; 1996-2000 and 2001-2005. As mega cities and major metro cities have earlier introduction times (Mashelkar et al., 2002) as well as a different fleet composition and mileage, we model emissions in the seven cities with more than five million inhabitants (New Delhi, Mumbai, Chennai, Kolkata, Bangalore, Hyderabad, and Ahmedabad) separately. For these 2 times 84 vehicle layers we derive exhaust emission factors for 10 compounds $\left(\mathrm{CO}_{2}, \mathrm{CH}_{4}, \mathrm{CO}\right.$, NMVOC, $\mathrm{NO}_{x}, \mathrm{SO}_{2}$, primary $\mathrm{PM}, \mathrm{PM}_{1}, \mathrm{BC}$ and $\mathrm{OC}$ )

\section{Modelling the vehicle fleet and its age composition}

Every motorised road vehicles in India needs to be officially registered; however the official registry represents the cumulative number of first registrations (Parikh and Radhakrishna, 2005). There is no de-registration of vehicles out of use nor are double registrations, e.g. after a change of the vehicle owner, deducted. In fact, the total registered number of vehicles is about $8 \%$ higher than the cumulated domestic sales between the years 1965 and 2005 (on the basis of TRW/MoSRTH, 2005 and SIAM, 2006, 2008).
For the purpose of the emission calculation we however need to know the rolling fleet by age bracket, as mass emission limits (exhaust) have been introduced since 1991.

Here we construct the rolling fleet from the annual number of domestic sales, differentiated by vehicle category. A so-called survival function models the vehicles' finite service life. The survival rate, i.e. the fraction of vehicles survived in the fleet after a certain age, normally decreases with this age. The following expression provides the number of vehicles actually circulating on road $(N)$ for the year $y$ :

$N_{v, y}=0.5 * D_{v, y}+\sum_{x=1965}^{y-1} D_{v, x *} S_{v,(y-x)}$

where $D$ is number of vehicles sold (domestic) and $S_{v,(y-x)}$ the survival rate of vehicle category $v$ for age $y-x$. Only half of the vehicles aged less than one year are taken to model the rolling vehicle fleet in the middle of the reference year 2005. Sales since 1965 have been included to better estimate the age distribution of the fleet.

Zachariadis et al. (1995 and 2001) have shown that, for Europe, the survival rate for a vehicle category can be best described by a modified Weibull distribution, i.e.

$S_{v, y-x}=P_{v}(y-x)=\exp \left[-\left(\frac{(y-x)+a_{v}}{T_{v}}\right)^{b_{v}}\right]$ and $P_{v}(0)=1$,

where $T$ is the characteristic service life of the vehicle, $a / b$ the failure steepness and the suffix $v$ the vehicle type. For the case with a high survival rate we set $a=0$, while the case with low survival rate is represented by $a=b$. The parameters ' $a$ ' or ' $T$ ' and ' $b$ ' assumed for Indian vehicles are presented in Table 2 . The survival rates modelled for heavy duty vehicles in India are presented in Fig. 2 as an example; they are compared to the survival functions used in Europe and the USA. The parameters for India are chosen to model in one case a longer and in the other case a shorter service life: A longer life of the vehicles could be explained by a sturdy mechanical frame and the fact that the vehicles are always repaired unless they have a fatal breakdown. A shorter service life compared to industrialised countries could be explained by heavier usage, higher accident rates and worse road conditions, all in all leading to more wear and breakdowns. The impact of a higher or lower estimate on the resulting emissions is analysed in the following.

According to our calculation only two thirds or maximum three quarters of the vehicles registered are actually circulating on the road (Fig. 3). The biggest absolute correction concerns motorized two wheelers, by far the most abundant vehicles in India: At least 10 million or up to 20 million units are not running any more on the road. The biggest relative correction however concerns busses and trucks: Only 53\% and 58\% of the registered numbers respectively are still running.

By age group, about $47 \%-53 \%$ of the vehicles still running were built after the year 2000 and about another 30\% after 1995; 11\%-14\% were built between 1991 and 1995 and 6\%-9\% prior (Fig. 4). The sharp increase in vehicle sales in India during the last decade strongly reduces the relative importance of older vehicles; in consequence also the variability between higher or lower survival rates is low. All this reduces the demand of highly accurate scrappage information.

\section{Vehicle fuel efficiency}

The average fuel efficiency per vehicle category relates with the annual mileage by the total fuel consumption. It is needed for a subsequent triangulation of the unknown mileage. Our values 
Table 2

Parameters assumed for survival rates of vehicles in India.

\begin{tabular}{|c|c|c|c|c|c|c|c|c|c|c|c|c|c|c|}
\hline \multirow{2}{*}{$\begin{array}{l}\text { Vehicle category } \\
\text { Survival rate }\end{array}$} & \multicolumn{2}{|l|}{ M2W } & \multicolumn{2}{|c|}{ Car gasoline } & \multicolumn{2}{|c|}{ Car diesel } & \multicolumn{2}{|l|}{ Bus } & \multicolumn{2}{|l|}{ M3W } & \multicolumn{2}{|l|}{ LDT } & \multicolumn{2}{|l|}{ HDT } \\
\hline & Low & High & Low & High & Low & High & Low & High & Low & High & Low & High & Low & High \\
\hline b & 1.99 & 2.55 & 2.03 & 2.64 & 2.39 & 2.64 & 2.29 & 3.21 & 1.94 & 2.04 & 1.99 & 1.99 & 2.29 & 3.44 \\
\hline $\mathrm{T}$ & 15.83 & 18.23 & 19.75 & 23.04 & 20.85 & 24.14 & 18.28 & 17.37 & 15.75 & 17.50 & 18.67 & 20.54 & 18.28 & 17.55 \\
\hline Resulting average age (years) & 5.73 & 6.55 & 6.34 & 7.10 & 5.92 & 6.69 & 7.46 & 7.62 & 5.78 & 6.41 & 4.08 & 4.29 & 7.78 & 7.96 \\
\hline
\end{tabular}

Low survival rate (SR): $a=b$; high survival rate: $a=0$ (cf. Formula 3).

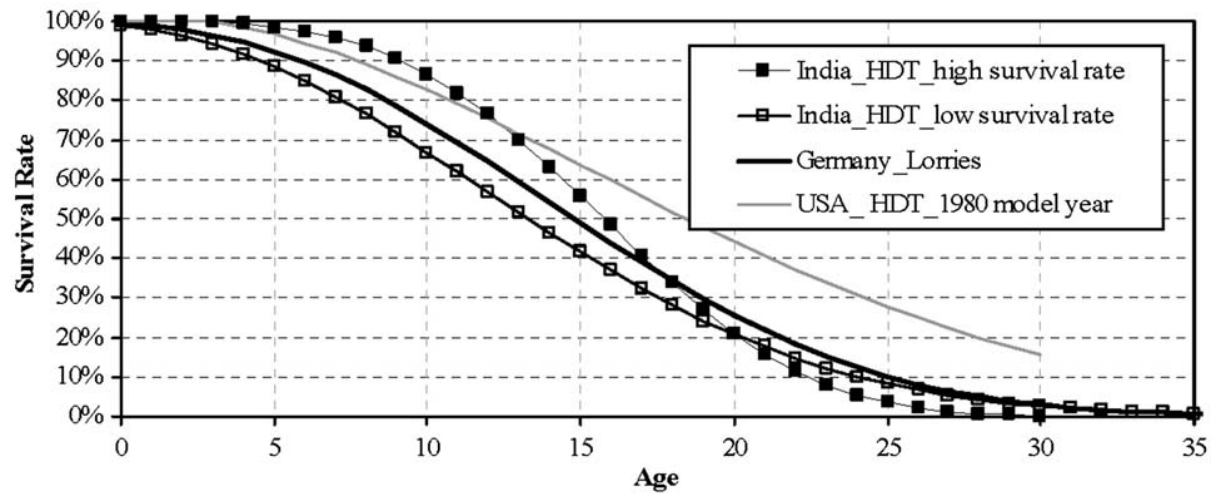

Fig. 2. Modelled survival rates for HDT for India and industrialised countries.
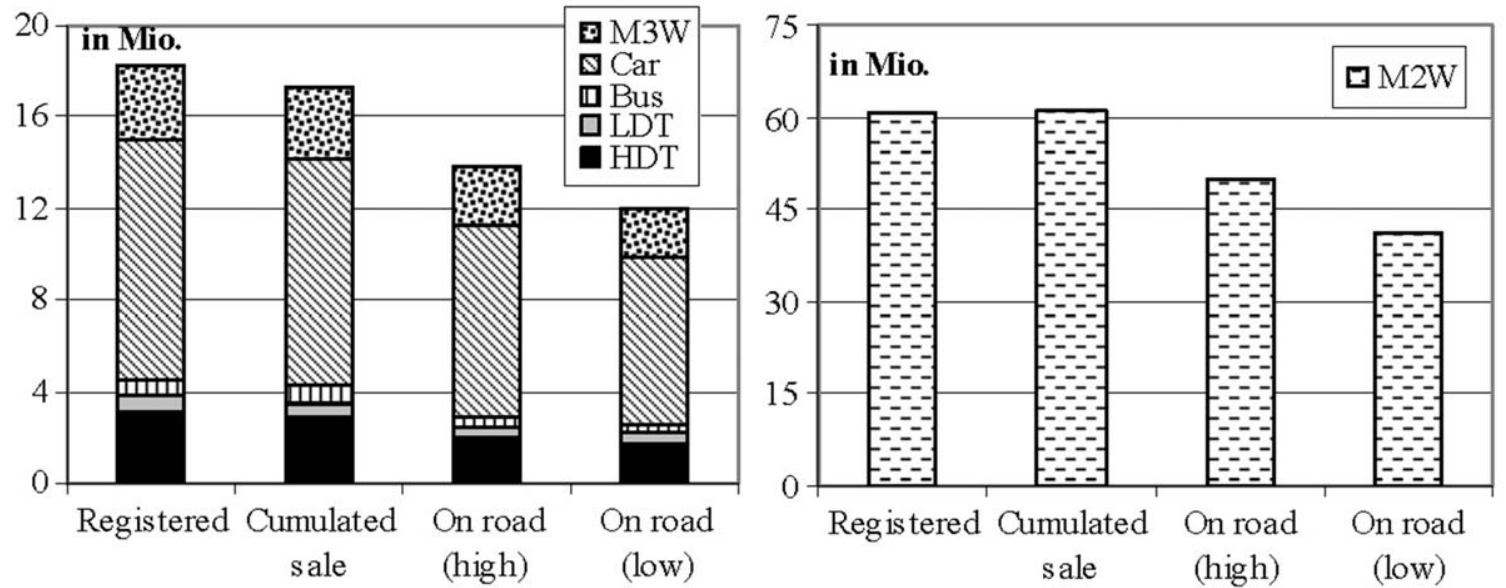

Fig. 3. Comparison of vehicles registered, cumulated sales, and modelled vehicles on road in India for y2005 (in mio.veh.).
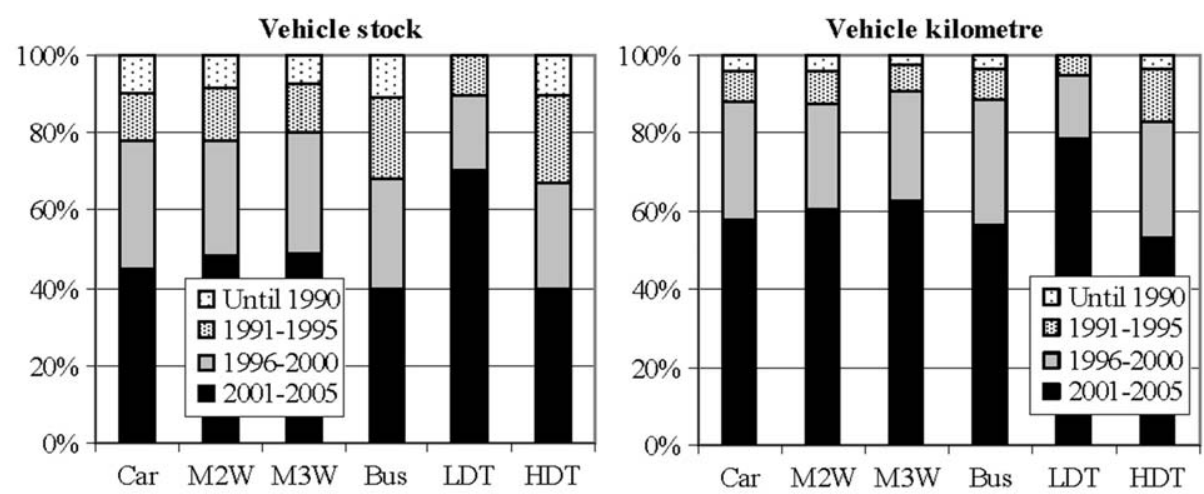

Fig. 4. Age composition of vehicles on road and of vehicle kilometre in India in the year 2005 
Table 3

Average fuel efficiency by vehicle sub-category and average annual mileage by vehicle category in India in the year 2005 .

\begin{tabular}{|c|c|c|c|c|c|c|c|c|c|}
\hline \multirow[t]{2}{*}{$\begin{array}{l}\text { Vehicle } \\
\text { details }^{\mathrm{a}}\end{array}$} & \multicolumn{3}{|c|}{$\begin{array}{l}\text { Fuel efficiencies }(\mathrm{g} / \mathrm{km}) \\
\text { in SAS literature }^{\mathrm{b}}\end{array}$} & \multirow[t]{2}{*}{$\begin{array}{l}\text { Fuel efficiencies, } \\
\text { This work }(\mathrm{g} / \mathrm{km})\end{array}$} & \multirow[t]{2}{*}{$\begin{array}{l}\text { Remarks for fuel } \\
\text { efficiencies in this work }\end{array}$} & \multicolumn{2}{|c|}{$\begin{array}{l}\text { Annual mileage in } \\
\text { Indian literature in } 1000 \mathrm{~km}^{\mathrm{c}}\end{array}$} & \multicolumn{2}{|c|}{$\begin{array}{l}\text { Modelled annual mileage } \\
\text { in this work (in } 1000 \mathrm{~km} \text { ) }\end{array}$} \\
\hline & Max. & Min. & Avg. & & & Max. & Min. & Mega cities & Rest of India \\
\hline Car, G & 88 & 52 & 73 & $77-81$ & Bottom-up calculation & 15 & 7.5 & $9.3-12.2$ & $9.2-10.4$ \\
\hline Car, D & 102 & 83 & 93 & 93 & Diesel cars are mostly bigger (SUVs). & & & & \\
\hline Car, CNG & & & & 77 & CNG scaled to gasoline & & & & \\
\hline M2W, G 2S & 22 & 11 & 16 & $15-21$ & SAS (Avg.-Max.) & 10 & 3.5 & $6.5-8.1$ & $5.4-6.4$ \\
\hline $\mathrm{M} 2 \mathrm{~W}, \mathrm{G} 4 \mathrm{~S}$ & 18 & 9 & 12 & $11-16$ & SAS average-90\%.of Max. & & & & \\
\hline M3W, G 2S & 67 & 21 & 35 & $26-38$ & $120 \%$ of $\mathrm{M} 3 \mathrm{~W} 4 \mathrm{~S}$ & & & & \\
\hline M3W, G 4S & 36 & 21 & 29 & $22-32$ & Range (SAS). & 44 & 19 & $36.9-46.6$ & $27.0-30.0$ \\
\hline M3W, D & & & & $20-34$ & CNG scaled to gasoline counterpart & & & & \\
\hline M3W, CNG & & & & $21-30$ & & & & & \\
\hline Bus, D & 272 & 189 & 238 & $238-286$ & SAS average-modelled Max. & 100 & 30 & $39.1-57.78$ & $55.6-62.5$ \\
\hline Bus, CNG & & & & $218-262$ & Scaled to diesel counterpart & & & & \\
\hline LDT, D & & & & $96-100$ & Comparable to diesel cars & 53 & 36 & $28.1-35.9$ & $25.9-37.5$ \\
\hline HDT, D & 267 & 164 & 222 & $222-244$ & SAS average to $+10 \%$ & 86 & 30 & $40.3-47.3$ & $53.1-59.6$ \\
\hline
\end{tabular}

${ }^{a} \mathrm{G}=$ gasoline, $\mathrm{D}=$ diesel, $2 \mathrm{~S}=$ Two stroke, $4 \mathrm{~S}=$ Four stroke, $\mathrm{M} 2 / 3 \mathrm{~W}=$ motorized two/three wheeler.

b Studied literature on fuel efficiencies in the South Asian (SAS) region: Shrestha and Malla (1996) for Kathmandu; Mittal and Sharma (2003) for India and the year

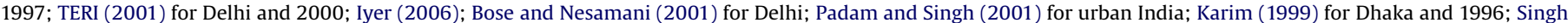
(2006) and Iyer and Badami (2007) for India. Conversion factors from $\mathrm{g} / \mathrm{km}$ to $\mathrm{l} / 100 \mathrm{~km}=0.1357$ for gasoline and 0.1176 for diesel.

c Studied literature on average annual mileages of vehicle categories: for India- Singh (2006) for the year 2000, RiTES (1999) for 1995-1988, Mittal and Sharma (2003)

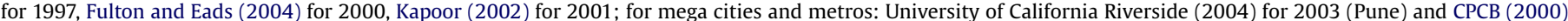

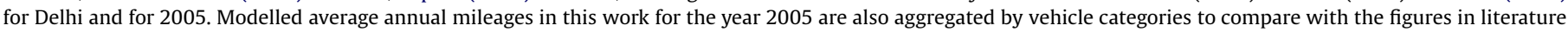
(e.g. mileage for M2W includes both $2 \mathrm{~S}$ and $4 \mathrm{~S}$ ).

are within $\pm 10 \%$ of the reviewed literature (Table 3 ); extreme values are dismissed. A range is used to account for differing driving conditions, i.e. urban road, extra urban road and highways, and for the age composition of each vehicle category. This will be used in the sensitivity analysis below.

\section{Triangulation of vehicle mileage with the total fuel consumed}

No representative data exists for the annual vehicle mileage but must be inferred from a few observations. Given the vehicle fleet and its average fuel efficiency, then the vehicle mileage is constrained by the total domestic fuel consumption. The consumption figure for motor gasoline is usually better determined as there are few other usages unlike the case of diesel fuel, that could also be used for electricity generation, in agriculture and fishing etc. However, though it is not quantified, it is well known that fuel adulteration plays a non-negligible role in India. A total of 3.6 million tonnes of kerosene (about $39 \%$ of the total consumption), a highly subsidised household fuel for the poor, was diverted to fuel adulteration and black marketing in the fiscal year 2005-06 in India (ASSOCHAM, 2006). Industrial chemicals e.g. Naptha and recycled lubricants are also used for adulteration (CPCB, 2003). The official Indian data and IEA (MiPNG, 2004:198; IEA, 2007) suggest an almost constant diesel consumption (21-22 Mtoe) in India since 1996. As this is incompatible with the strong growth in vehicle stock, this number is dismissed. Garg et al. (2006) give a figure of 9 Mtoe gasoline and 44.5 Mtoe diesel consumption. Singh et al. (2008) estimate that $70 \%$ of the diesel is used for road transportation, i.e. resulting in about 31 Mtoe. We take these figures as indicative of the total consumption. Again a careful analysis is needed to decide between conflicting data.

The average vehicle mileage has been derived to be compatible with (i) the available literature (summarised in Table 3) and (ii) the estimated reference fuel consumption. This results in a total consumption of 9.8-10.3 Mtoe gasoline and of 34.2-37.7 Mtoe diesel. The excess to the reference amounts can be attributed to the unrecorded and adultered fuel. The excess gasoline also includes lubricants for two-stroke motorized two and three wheelers, which was about $2 \%$ of total gasoline used in the year 2000 (Singh et al., 2008). CNG/LPG consumption estimated by the model ranges from 0.51 to 0.58 Mtoe (about $1 \%$ of total fuel consumption). Our calculated fuel consumption is rather a lower limit of the actual consumption: Literature values for the annual vehicle mileage are often higher than we assumed, but none is based on up-to-date representative surveys.

The average vehicle mileage is allocated to the four age groups in each vehicle category (Baidya, 2008a for more details). The mileages change linearly with age in the reference case, in which the average annual mileage more or less falls in the mid point of age group 1996-2000. Two more rates of age-depreciation for the annual mileage are allocated for sensitivity analyses: (i) less skewed than the reference case and (ii) exponential. As older vehicles are driven less than younger ones, their shares in mileage are about half their share in stock. The contribution to vehicle kilometres are $54 \%-69 \%, 24 \%-29 \%, 5 \%-11 \%$ and $2 \%-6 \%$ by the age groups 2001-2005, 1996-2000, 1991-1996 and until 1990 (Fig. 6).

\section{Deriving emission factors}

Our classification aims to group vehicles with respect to similar emission behaviour on the one hand, while being constrained by the availability and reliability of the data on the other hand. Here we account for the following most important factors within each vehicle category: Fuel or engine concept, engine technology in terms of two or four stroke principle, the legislative emission standard or the emission control technology, the average maintenance or deterioration of engine and emission control system. The driving conditions are approximated by average speeds on urban and extra-urban roads. As vehicle characteristics and age, its maintenance and inspection, but also driving conditions differ; these factors have been derived separately for mega cities and the rest of the country. 
Table 4

Emission factors by vehicle category and age group in India outside 7 biggest cities ${ }^{(a)}$ for the year 2005 (reference case).

\begin{tabular}{|c|c|c|c|c|c|c|c|c|c|c|c|c|c|c|c|c|c|c|}
\hline \multirow[t]{2}{*}{ in $\mathrm{g} / \mathrm{vkm}$} & \multicolumn{4}{|l|}{$\mathrm{CO}$} & \multicolumn{4}{|l|}{$\mathrm{HC}$} & \multicolumn{4}{|l|}{$\mathrm{NO}_{x}$} & \multicolumn{4}{|l|}{ PM } & \multirow[t]{2}{*}{$\mathrm{CO}_{2}$} & \multirow[t]{2}{*}{$\mathrm{SO}_{2}$} \\
\hline & $\mathrm{A}^{(\mathrm{b}, \mathrm{c})}$ & $\mathrm{B}^{(\mathrm{b})}$ & $C^{(b)}$ & $\mathrm{D}^{(\mathrm{b})}$ & A & B & C & D & A & B & C & D & A & B & C & D & & \\
\hline Car, $\mathrm{G}(\mathrm{d})$ & 2.72 & 14.30 & 19.31 & 42.00 & 0.45 & 1.96 & 3.32 & 4.35 & 0.69 & 0.98 & 1.80 & 1.93 & 0.06 & 0.07 & 0.09 & 0.10 & 242 & 0.080 \\
\hline Car, $\mathrm{D}(\mathrm{d})$ & 2.72 & 3.00 & 4.05 & 15.00 & 0.17 & 0.74 & 1.11 & 1.11 & 1.00 & 1.10 & 2.77 & 2.77 & 0.19 & 0.46 & 0.77 & 1.03 & 237 & 0.149 \\
\hline Taxi, CNG & 1.71 & 3.14 & 4.24 & 9.43 & 0.002 & 0.002 & 0.002 & 0.002 & 0.30 & 0.30 & 0.30 & 0.30 & 0.01 & 0.01 & 0.01 & 0.01 & 196 & 0.000 \\
\hline $\mathrm{M} 2 \mathrm{~W}, 2 \mathrm{~S}$ & 2.00 & 18.70 & 25.25 & 28.66 & 2.70 & 5.71 & 6.47 & 6.96 & 0.08 & 0.08 & 0.04 & 0.04 & 0.18 & 0.26 & 0.32 & 0.46 & 44 & 0.014 \\
\hline $\mathrm{M} 2 \mathrm{~W}, 4 \mathrm{~S}$ & 2.00 & 11.00 & 14.85 & 29.00 & 0.95 & 2.13 & 2.13 & 2.13 & 0.20 & 0.29 & 0.29 & 0.29 & 0.06 & 0.08 & 0.10 & 0.14 & 33 & 0.011 \\
\hline M3W, 2S & 5.20 & 20.00 & 27.00 & 40.00 & 3.56 & 8.00 & 12.00 & 14.00 & 0.16 & 0.15 & 0.10 & 0.10 & 0.46 & 0.52 & 0.63 & 0.70 & 78 & 0.026 \\
\hline M3W, 4S & 4.00 & 17.00 & 22.95 & 30.00 & 1.90 & 4.25 & 4.25 & 4.25 & 0.30 & 0.10 & 0.10 & 0.10 & 0.11 & 0.16 & 0.20 & 0.28 & 65 & 0.021 \\
\hline M3W, D (e) & 3.60 & 5.00 & 6.75 & 20.00 & 0.17 & 0.74 & 1.11 & 1.11 & 0.50 & 0.55 & 1.39 & 1.39 & 0.20 & 0.70 & 0.90 & 1.00 & 76 & 0.048 \\
\hline M3W, CNG & 2.05 & 3.77 & 5.09 & 0.00 & 0.003 & 0.003 & 0.003 & 0.003 & 0.20 & 0.20 & 0.20 & 0.20 & 0.01 & 0.01 & 0.01 & 0.01 & 52 & 0.000 \\
\hline Bus, D & 4.50 & 5.50 & 7.43 & 12.70 & 1.55 & 3.70 & 3.70 & 3.70 & 12.00 & 13.49 & 13.49 & 19.00 & 0.59 & 1.49 & 2.48 & 3.30 & 757 & 0.476 \\
\hline Bus, CNG & 3.60 & 4.40 & 5.94 & 0.00 & 0.01 & 0.01 & 0.01 & 0.01 & 1.00 & 1.00 & 1.00 & 1.00 & 0.19 & 0.19 & 0.19 & 0.19 & 557 & 0.000 \\
\hline LDT, D(e) & 3.54 & 5.00 & 6.75 & 11.48 & 0.32 & 1.40 & 1.40 & 1.40 & 0.85 & 2.89 & 4.80 & 4.80 & 0.17 & 0.21 & 1.00 & 1.33 & 306 & 0.192 \\
\hline HDT, D & 4.50 & 6.35 & 8.57 & 11.48 & 1.55 & 2.20 & 2.20 & 2.20 & 8.86 & 13.17 & 13.17 & 19.00 & 0.49 & 1.22 & 2.03 & 2.70 & 706 & 0.444 \\
\hline Tractor(f) & 0.18 & & & & 0.10 & & & & 0.21 & & & & 0.05 & & & & 3 & 0.002 \\
\hline
\end{tabular}

Vehicles manufactured: $A=2001-005, B=1996-000, C=1991-995, D=$ Before 1991.

$\mathrm{G}=$ gasoline, $\mathrm{D}=$ diesel, $\mathrm{CNG}=$ Compressed natural gas, $2 \mathrm{~S}=$ Two stroke, $4 \mathrm{~S}=$ Four stroke, $\mathrm{M} 2 / 3 \mathrm{~W}=$ motorized two/three wheeler.

Assumptions for estimating emission factors:

(a) 7 biggest cities have lower emission factors for the age groups $\mathrm{A}$ and $\mathrm{B}$.

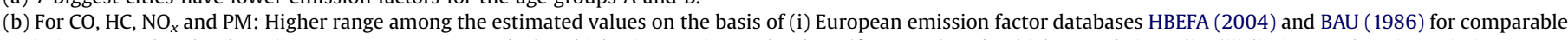

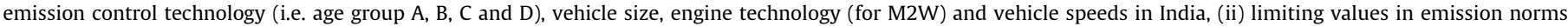
introduced in India, (iii) CPCB (2000), (iv) Faiz et al. (1996) and Kojima et al. (2000).

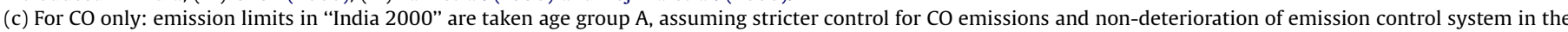
youngest vehicles in the reference case.

(d) Cars include passenger cars, light passenger van, SUV and taxis.

(e) Emission factors for Diesel M3W and LDT are derived by comparing with diesel cars.

(f) Tractor emission factors (uncontrolled technology) in grams/kg diesel consumed, Source: IFEU (2004).

Emission factors for each vehicle sub-group have been derived for the four age groups, representing the time development of Indian emission standards. For urban roads, an average speed range of $13-23.5 \mathrm{~km} / \mathrm{h}$ has been assumed for different vehicle types and driving conditions (based on University of California Riverside, 2004). The average speed of vehicles in the national and state highways of India (both are not expressways) ranges between $40-50 \mathrm{~km} / \mathrm{h}$. The emission factors are derived from the surveyed literature on emission measurement programs and emission factor estimations in the South Asian and South East Asian regions (Table 4 presents the emission factors as well as the assumptions. See Baidya, 2008a for the same for mega cities).

In terms of vehicle number and mileage, M2W and M3W built before 2001 form the most important category. They are without dedicated emission control, i.e. pre EURO, and mostly powered by two stroke engines. Emission factors for two-stroke M2W in a particular age group are weighted averages over the mix and emission factors of mopeds, two stroke scooters, and motorcycles. (Mopeds have exclusively two stroke engines of less than $50 \mathrm{cc}$. The majority of scooters and motorcycles have 75-125 cc engines). The same process has been followed for calculating the emission factors of four stroke scooters and motorcycles. Four stroke M2W and $\mathrm{M} 3 \mathrm{~W}$ represent a more advanced though somewhat more expensive engine concept. Most of them are younger (built after 2001), and complying with the (equivalent) EURO I norm. Hence, their emission factors are significantly lower.

HDT are the other important vehicle category for Indian road transport. Most of them are medium duty trucks up to the prescribed limit of 12 tons GVW; however heavy overloading is common. This, together with bad, congested or very mixed road conditions leads to slow driving speeds and high engine loads in many parts of the country. The annual mandatory fitness test is focused on basic mechanical and safety aspects. Adulteration of transport fuel also increases exhaust emissions, more importantly from new engines. Hence, all factors together result in high unit emissions even for new vehicles and a high deterioration over time.

The fleet of passenger cars consists of a base of cars built before 1995 and a quickly growing stock of modern cars complying with the EURO I equivalent emission norm. Cars in the mega cities, where purchasing power is higher and car commuting preferred to public transport, are younger than in the rest of the country. For new vehicles we can therefore transfer emission factors from recent vehicles in Europe. For old(er) cars we have to apply emission factors for uncontrolled technology, which is comparable to vehicles in Europe before the emission regulations began. Hence for passenger cars, heavy duty vehicles and buses produced before 1991, we transfer emission factors representative of European vehicles of the mid to late 1970'ies, and for Indian vehicles of the nineties we transfer emission factors representative of European vehicles in the mid eighties (BAU, 1986), each with Indian road speeds. A medium level of enforcement in emission control legislation is assumed for new vehicles (age $<5$ years) and in general a higher deterioration and/or less maintenance than under European conditions.

There are more than 2 million tractors in India. They are important road vehicles in the rural India, where about 740 million people live. Emission norms for tractors were introduced in October 2005 only. Therefore, emission factors for the uncontrolled emission technology are used for tractors.

In the year 2005, sulphur contents of on average 150 and $350 \mathrm{ppm}$ (Gupta, 2001) are assumed for gasoline and diesel in mega cities, and of $500 \mathrm{ppm}$ (ADB, 2008) and $1000 \mathrm{ppm}$, respectively for the rest of the country (double of the targeted value for diesel considering adulteration). $\mathrm{CO}_{2}$ and $\mathrm{SO}_{2}$ emission factors are calculated on the assumption of complete combustion of the $\mathrm{C}$ and $\mathrm{S}$ atoms contained in the fuel. $\mathrm{PM}_{1}, \mathrm{BC}$ and $\mathrm{OC}$ are calculated as fractions of our own PM emission factor. We use the fractions as $0.86,0.66$ and 0.34 for $\mathrm{PM}_{1}, \mathrm{BC}$ and $\mathrm{OC}$ for diesel vehicles, $0.85,0.34$ and 0.36 for gasoline and $0.95,0.05$ and 0.79 
for gasoline two-stroke vehicles respectively as proposed by Bond et al. (2004). $\mathrm{CH}_{4}$ emission factors are derived as fractions of our hydrocarbon emission factors, which are highest for two stroke gasoline and CNG vehicles and lowest for diesel buses. They are 0.05 for passenger car, 0.03 for LDT and HDT, 0.02 for bus and 0.09 for M2W and M3W.

\section{Total emissions from road transportation}

The multiplication of all factors derived in the preceding chapters gives the total national emissions from road transportation in India in the year 2005. Motorised traffic consumed about $48.3(+0.2 /-4)$ Mtoe of motor fuels including about 8 Mtoe adulterated fuels, resulting in the emission of $146(+0.5 /-12) \mathrm{Tg}$ $\mathrm{CO}_{2}, 122(+46 /-28) \mathrm{Gg} \mathrm{CH}_{4}, 4909(+4349 /-1567) \mathrm{Gg} \mathrm{CO}$, 1503(+542/-410)Gg NMVOC, $1981(+564 /-443) \mathrm{Gg} \mathrm{NO}_{x}, 55$ (-5) Gg SO, $274(+169 /-75) \mathrm{Gg}$ PM, $241(+148 /-66) \mathrm{Gg} \mathrm{PM}_{1}, 123$ $(+82 /-34) \mathrm{Gg} \mathrm{BC}$ and $82(+45 /-23) \mathrm{Gg}$ OC. Passenger transportation consumes about 39\% of the total fuel (half of which is gasoline) but emits four fifths of CO and NMVOC, more than $90 \%$ of $\mathrm{CH}_{4}$ and $64 \%$ of OC. Freight transportation runs entirely on diesel and emits three quarters of $\mathrm{NO}_{x}$ and $\mathrm{BC}, 60 \%$ of $\mathrm{PM}$ and more than two thirds of $\mathrm{SO}_{2}$.

For each compound the relative contribution of each vehicle category is different (Fig. 5); this illustrates the importance of a differentiated approach. Grossly, one can distinguish a group of species related to the incomplete combustion typical for spark ignition engines, here $\mathrm{CO}$, hydrocarbons and OC. About two thirds to three quarters of their total emissions stem from motorised two wheelers and three wheelers, though they account only for about half of total gasoline consumed. This reflects both the high usage and the high unit emissions from these vehicles. Diesel vehicles, burning at higher temperatures under excess of air, dominate emissions of $\mathrm{NO}_{x}, \mathrm{PM}$ and $\mathrm{BC}$. Since three times more diesel is consumed than gasoline and its sulphur contents is also three times higher, diesel vehicles also dominate emissions of $\mathrm{SO}_{2}$. More precisely, it is heavy duty trucks and busses that determine the national total emissions. Tractors add another $10 \%, 18 \%$ and $22 \%$ of $\mathrm{NO}_{x}, \mathrm{PM}$ and $\mathrm{BC}$, respectively in rural areas. These sizeable shares justify their inclusion in the emission calculation. Passenger cars have, despite their rapid growth, so far only a limited influence on the total emissions: They account for $12 \%$ of $\mathrm{CO}, 9 \% \mathrm{SO}_{2}, 5 \%$ hydrocarbons, $4 \% \mathrm{NO}_{x}$, PM and $\mathrm{BC}$ and only $3 \% \mathrm{OC}$. Their shares are however significantly higher in the big cities, i.e. the country's economic centres (Appendix B1).
The big cities and their passenger vehicles have so far received most attention in India when it comes to pollutant emissions from road transportation. Here we present a first quantitative calculation of their shares relative to the national total: Vehicles in the seven mega cities together consume about 9\% diesel, $27 \%$ gasoline, and $96 \% \mathrm{CNG} / \mathrm{LPG}$ of the national totals and emit $14 \% \mathrm{CO}_{2}$ and $\mathrm{CO}$, $13 \%$ hydrocarbons, $9 \% \mathrm{NO}_{x}$ and $\mathrm{OC}, 8 \% \mathrm{PM}, 7 \% \mathrm{BC}$ and $6 \% \mathrm{SO}_{2}$. Given that only $6 \%$ of the population lives there, these cities are clearly centres of transport activity. Thanks to more stringent emission norms and higher fuel quality, more modern vehicles, a different fleet mix, a high share of CNG use in busses, M3Ws and taxis as well as restrictions on HDT the related pollutant emission rates in the mega cities are not even higher. However, our calculation also points to the facts that (i) $85 \%-90 \%$ of all pollutant emission rates are due to traffic outside the big metropoles, (ii) that trucks are a very important pollutant source, and (iii) that CNG and lower sulphur contents may be local solutions but have no significant impact at the national level.

Vehicles produced until 1995 drive $12 \%$ of total mileage, consume about $14 \%$ fuel and emit 32\% CO, 26\% hydrocarbons, 20\% $\mathrm{NO}_{x}, 30 \% \mathrm{PM}$ and $8 \% \mathrm{SO}_{2}$ in the reference case (see Fig. 6 for the upper and lower shares). Vehicles built between 1996 and 2000 are the most important age group, since they are ill-maintained, uncontrolled but drive considerably higher than the older ones. They drive $28 \%$ of total mileage, consume $30 \%$ of the fuel and emit $47 \% \mathrm{CO}, 43 \%$ hydrocarbons, $35 \% \mathrm{NO}_{x}, 38 \% \mathrm{PM}$ and $16 \% \mathrm{SO}_{2}$.

\section{Sensitivity analyses}

Our calculation is based on a number of assumptions as derived in the preceding chapters. However, only some are important for the resulting emissions. Here, we systematically check the influence of different plausible (i) stock assumptions, (ii) vehicle mileages, and (iii) vehicle emission factors.

Our reference case is defined by: (a) high survival rates for the vehicle stock, (b) a moderate decrease of annual mileage by age, and (c) moderate level of enforcement for 0-4 year's old vehicles (EURO 1 equivalent for the rest of the country and 50\% EURO 2 equivalent in the mega cities). These assumptions result in a higher number of older vehicles in use and moderately stringent unit emissions. In the following we change one assumption at a time and leave all other parameters constant (Fig. 7):

(i) Using a low survival rate as has been defined above, would correspond to a quicker breakdown or replacement of older

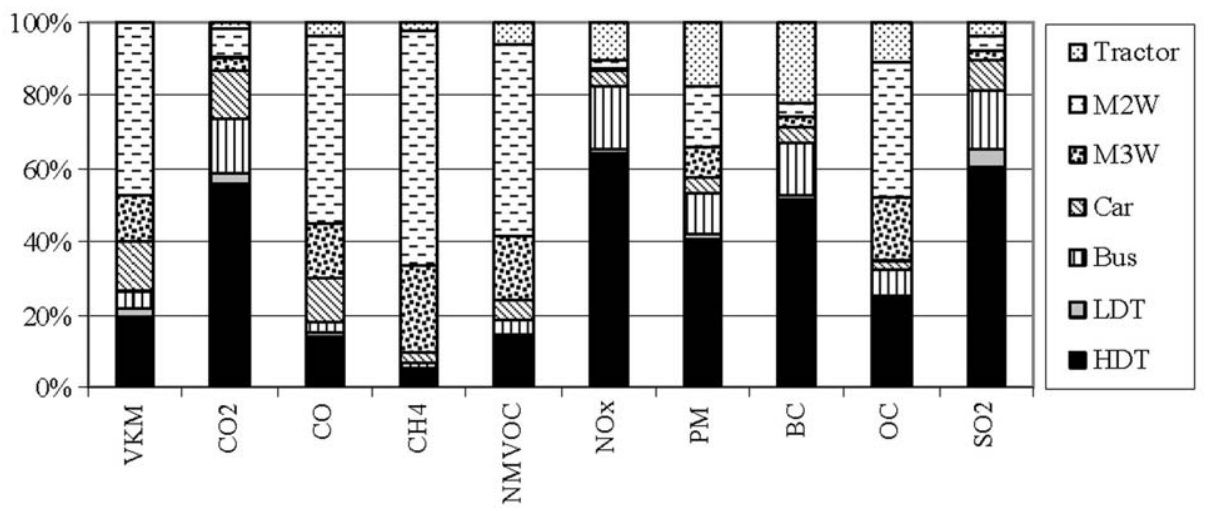

Fig. 5. Shares of vehicle kilometre and exhaust emissions by vehicle category in India in the year 2005 (reference case). 


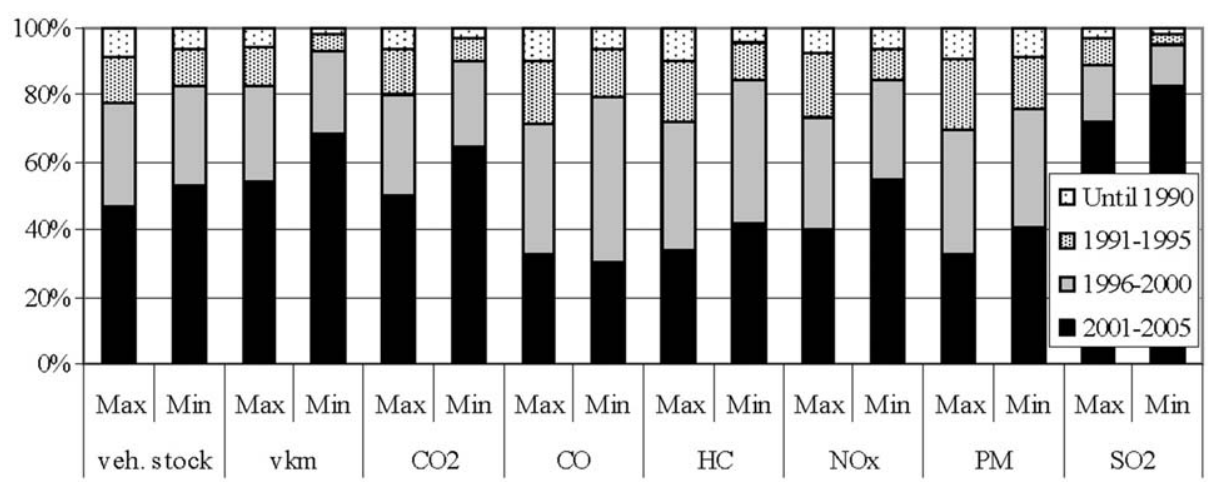

Fig. 6. Sensitivity of vehicle stock, vehicle kilometre, and emissions to the age composition in India in the year 2005 (maximum and minimum cases).

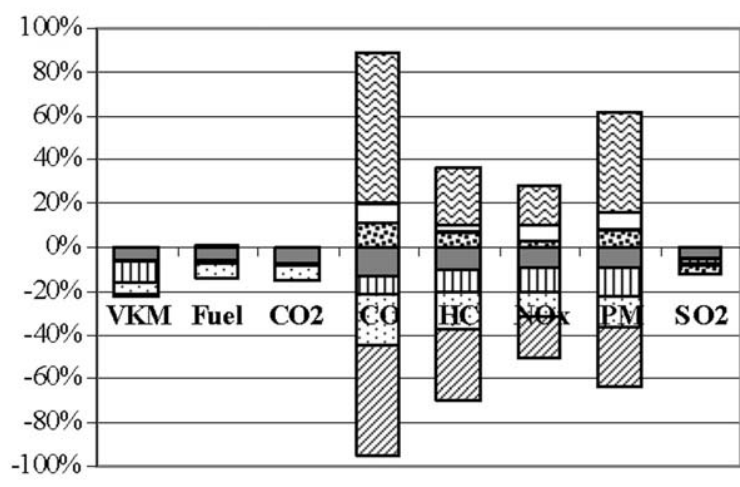

$\square$ Low inspection \& maintenance
als o in $>4$ years old vehicles
$\square$ Low inspection \& maintenance in
$10-14$ years old vehicles
⿴ Higher mileage of old v ehicles
$\square$ With CPCB (2000) emis sion factors
$\square$ Higher mileage of new vehicles
$\square$ Low average annual mileage
$\square$ Change in survival rates

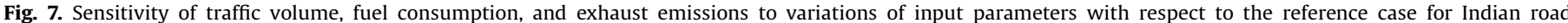
transportation in the year 2005.

vehicles. In consequence both the total stock number and the share of older vehicles would be lower, and hence the fleet average emission factor. When the same total fuel is consumed then a low vehicle survival rate results in lower total exhaust emissions. The difference to the reference case ranges from $-5 \%$ to $-13 \%$ across the compounds, depending on the vehicle mix.

(ii) The uncertainty in the vehicle mileage is threefold: A lower average mileage would result in lower total fuel consumption and proportionally less exhaust emissions. We estimate the range from $-1 \%$ to $-13 \%$. Keeping the average mileage per vehicle category fixed but assuming a higher mileage share of newer and less polluting vehicles, means less total exhaust emissions. Inversely, when the mileage share of older vehicles is higher than in our reference case, the resulting exhaust emissions will be higher. The uncertainty due to mileage variations is estimated as $(-11 \%,+3 \%)$ for $\mathrm{NO}_{x}$ and up to $(-23 \%,+12 \%)$ for CO. Again, the uncertainty is limited as this variation is constrained by plausibility and the total fuel available.

(iii) The biggest uncertainty concerns the average emission factor. Assuming higher unit emissions from the oldest vehicles, i.e. modelling higher super-emitters, would increase CO emissions by about $9 \%$ but $\mathrm{HC}$ emissions by as low as $2 \%$. The impact is only limited as the fleet and hence the average emission factor is dominated by the higher number of new vehicles. However, assuming less maintenance and a higher deterioration across the whole fleet significantly affects the resulting total emissions: $\mathrm{NO}_{x}$ emissions may increase by $19 \%$, while CO emissions might increase by as much as $68 \%$. Inversely, assuming as low emission factors as CPCB (2000) for Delhi, i.e. a much higher level of maintenance in the whole country, would result in $-20 \%$ lower total $\mathrm{NO}_{x}$ and $-51 \%$ lower CO emissions. The overall variation in emissions is large as the vehicle emission factors are not constrained by anything, notably not by the fuel consumed. The high variations in $\mathrm{CO}$ and PM are due to large differences in the emission factors of vehicles until and after 2000, the first year of the more stringent EURO I equivalent emission norms; this concerns primarily $\mathrm{M} 2 \mathrm{~W}$ and $\mathrm{M} 3 \mathrm{~W}$ for CO and HDT and busses for PM (cf. Table 4). Hence the emission calculation for these pollutants is particularly sensitive to the assumptions.

In summary, the biggest uncertainty in total emissions is related to the uncertainty of the fleet average emission factors. For $\mathrm{NO}_{x}$ this range is lowest with about $\pm 20 \%$; the range is highest for CO with $-51 \%$ to $+68 \%$. Hence, most care should be devoted to the determination of the average emission factor. As possible variations in the average mileage and the mileage distribution between the age groups are constrained by the available fuel, the resulting uncertainty is a factor of two to three lower. Therefore, our assumptions with respect to mileage are not critical. Similarly, the 
uncertainty in modelling total stock and its age distribution has only a limited influence as long as the total fuel consumption and the related mileage is constrained by the national fuel balance. This justifies our assumptions and points again to the crucial role of fuel calibration. Inversely, emission inventories without a calibration to the national fuel balance will be prone to much higher uncertainties on top of the unavoidable uncertainty with respect to reference emission factors.

\section{Results in the Indian context}

On the basis of our detailed analysis we can now review the other emission calculations for Indian road transport (Table 1). Our value of $48.3(+0.2 /-4)$ Mtoe fuel consumption in the year 2005 is the highest; the estimates from Fulton and Eads (2004) and Garg et al. (2006) fall within this range, and consequently the calculated $\mathrm{CO}_{2}$ emissions concur. The $\mathrm{CO}_{2}$ estimate in ADB (2006) is surprisingly high. The emission factors for $\mathrm{NO}_{x}$ lay for all sources within our uncertainty range. Far outside this range are the PM factor from Garg et al. (2006), the CO factor from Fulton and Eads (2004) and the $\mathrm{SO}_{2}$ emission factor from IIASA (2008); we cannot confirm these estimates. The $\mathrm{HC}$ emission factor from Fulton and Eads (2004) must be higher than ours as it includes evaporative emissions.

To have more data we include emissions for the year 2000. We divide our values for the year 2005 by 1.37, the growth rate of the GDP of India between 2000 and 2005 (IMF, 2008). Thus, we derive indicative $\mathrm{CO}_{2}$ emissions of $106(+0.4,-9) \mathrm{Tg}$ for the year 2000 . Relative to this value, the estimates by Garg et al. (2006) and Van Aardenne et al. (2005) are about 10\% higher, while Ohara et al. (2007) are more than 10\% lower than our lower limit. Such values could only be justified if the transport volume growth had been much less (below 20\%) or much higher (more than 55\%) than the GDP growth, which both is implausible, besides being incompatible with each other. The $\mathrm{CO}_{2}$ estimates by IIASA (2008), Singh et al. (2008) and Borken et al. (2007, 2008) fall well within our range and can thus be confirmed. However, the emission factors used by Singh (2006) are slightly outside our lower limit for $\mathrm{NO}_{x}$ and significantly too low for HC. Our average PM emission factor has increased as now higher emissions from gasoline two-stroke M2W and M3W, from diesel M3W, and notably from tractors are included, and a higher deterioration has been assumed than previously (Borken et al., 2007, 2008). Ohara et al. (2007) use emission factors for $\mathrm{CO}, \mathrm{HC}$ and $\mathrm{SO}_{2}$ well outside our upper range. Hence, despite a much lower activity rate as indicated by their $\mathrm{CO}_{2}$ totals, their resulting $\mathrm{CO}, \mathrm{HC}$ and $\mathrm{SO}_{2}$ emissions for Indian road transport are even higher than our reference values. Likewise, the PM emission factors by Garg et al. (2006) and the $\mathrm{SO}_{2}$ value by Van Aardenne et al. (2005) seem to refer to a very different vehicle technology and cannot be confirmed by our calculation here.

In this way our detailed bottom-up calculation can be used to cross-check other inventories, either from national, regional or global outreach, and point to the most important sources for discrepancy: The activity data in the first place, and the emission factors notably for $\mathrm{CO}, \mathrm{HC}$ and to some extent also for $\mathrm{PM}$ and $\mathrm{SO}_{2}$. Vice versa, calculations for $\mathrm{NO}_{x}$ are very consistent.

\section{Summary}

This bottom-up inventory brings the calculation of road transport's exhaust emissions in India one step further to a sophisticated modelling that is standard for industrialised countries. It lends itself for further improvement and differentia- tion, but already provides novel quantitative detail. The average vehicle age is about 6 years for motorized two wheelers and motorized three wheelers, between 6 and 7 years for cars, and 7.5-8 years for busses and heavy duty trucks. In generalising, this situation is typical for a boom from relatively low levels as also encountered in China and South East Asian countries. The uncertainty in the age composition of the fleet translates to about $5-10 \%$ uncertainty in emission totals. This limited uncertainty reduces the need for a more accurate determination of the running fleet, as long as the total fuel consumption is relatively well known. A far bigger uncertainty stems from the large spread in emission factors.

If emissions of unburnt $\mathrm{HC}, \mathrm{OC}$ and $\mathrm{CO}$ are to be reduced, the 2-stroke two wheelers are the most obvious target. Similarly, addressing $\mathrm{NO}_{x}, \mathrm{PM}$ and $\mathrm{BC}$ requires measures on trucks and busses. One way could be to enforce the mandatory inspections and to include a comprehensive emission testing. A nationwide, reliable system of inspection and maintenance would also be an important measure to control emissions from the fleet of younger vehicles that will still be in use for several years: High extra emissions result from a quick deterioration of their emission control system. We estimate a related reduction potential of $40 \%$ for $\mathrm{NO}_{x}$ and up to $80 \%$ for $\mathrm{CO}$ emissions. As India continues with setting more and more stringent emissions norms for new vehicles, this will only have a lasting effect if accompanied by a reliable system of maintenance. The current inspection practice definitely needs to be made more comprehensive, for instance including trucks and busses. This requires a higher training of the people implementing it as much as it requires infrastructure and adequate financial, political and public support.

For fuel consumption and $\mathrm{CO}_{2}$ emissions trucks are the single most important vehicle category, followed by busses and the quickly growing car segment. If the growth shall be contained then the discussed fuel efficiency standards may be a good way provided they can be made stringent enough (cf. Baidya, 2008b). However, if they do not address commercial vehicles, they will leave out the dominant vehicle category. Furthermore, push and pull measures are needed to maintain and significantly improve public transport, the efficiency of the operation and of the transport system. However, with India's motorization taking off, this is hard to imagine.

\section{Acknowledgements}

We gratefully acknowledge the financial support from the European Union Research Programme within the Integrated Project "QUANTIFY-Quantifying the Climate Impact of Global and European Transport Systems" (http://www.pa.op.dlr.de/quan tify) and from DLR. We particularly thank the coordinator R. Sausen (DLR Oberpfaffenhofen) and R. Kühne (DLR Berlin) for their support and acknowledge the helpful discussions with R. Bose (formerly TERI, Delhi), R. Friedrich (IER Stuttgart), N.V.Iyer (Pune), T. Meretèi (KTI Budapest), M.M. Pathak and S. Ramakrishna (both CIRT Pune), G.K. Sharma (formerly CIRT Pune, now NATRIP Delhi), K.L. Thapar (AITD, Delhi), K.U. Thiessenhusen (IPA Potsdam) and numerous other experts in India. 


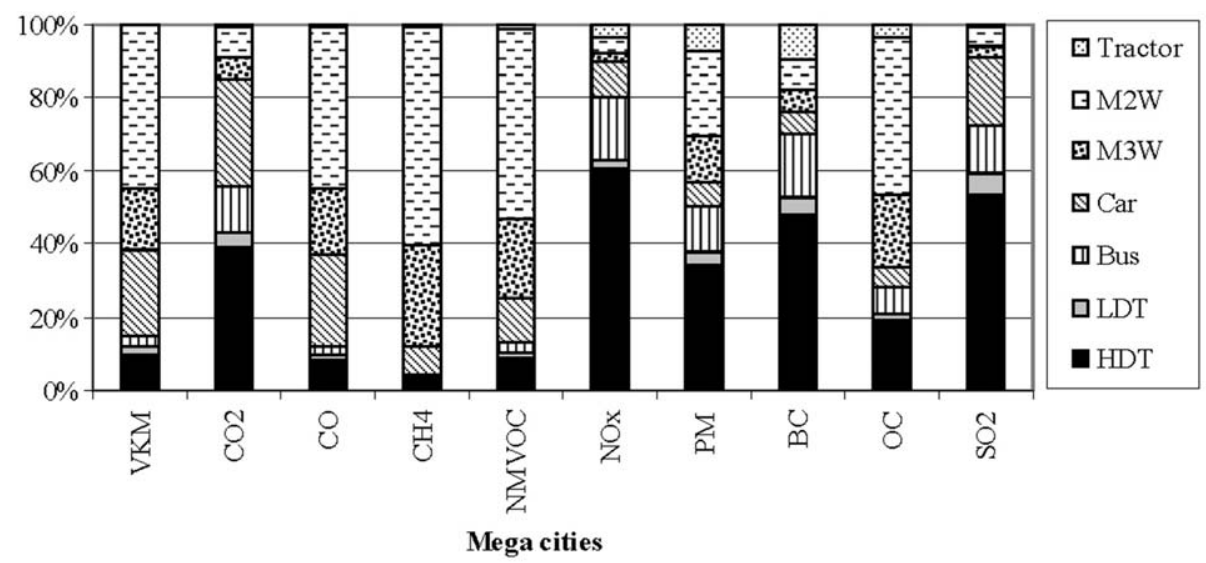

Fig. B1. Shares of vehicle kilometre and exhaust emissions by vehicle category in seven biggest cities in India in the year 2005 (reference case).

\section{References}

ADB, 2006. Energy Efficiency and Climate Change Considerations for on-Road Transport in Asia. Asian Development Bank, Manila, Philippines.

ADB, A., 2008. Vehicle Emissions Reduction/Country Data of India. Asian Development Bank, Manila, Philippines Available at: 〈http://www.adb.org/ vehicle-emissions/IND/fuel.asp\#dsl $\rangle$, accessed 15.03.2008.

ASSOCHAM (Associated Chambers of Commerce and Industry of India), 2006. Press release, August 02, 2006: 38.6\% of kerosene subsidy being diverted for black marketing. Available at: 〈http://www.assocham.org/prels/shownews.php?id= $646>$

Baidya, S., 2008a. Trace gas and particulate matter emissions from road transportation in India. Faculty of Civil- and Environmental Engineering, University of Stuttgart, Germany (PhD dissertation).

Baidya, S., 2008b. Fuel efficiency of light duty vehicles in India: Uncertainties in transforming stock. Workshop on 'New energy indicators for transport: The way forward', 28-29 January, Paris. International Energy Agency and International Transport Forum, Paris.

BAU, 1986. Schadstoffemissionen des privaten Strassenverkehrs 1950-2000. Schriftenreihe Umweltschutz Nr. 55. Dokumentationsdienst, Bundesamt für Umweltschutz, Bern (in German).

Bhattacharya, S., Mitra, A.P., 1998. Greenhouse Gas Emissions in India for Year 1990. Centre on Global Change. National Physical Laboratory, New Delhi, India.

Bond, T.C., Streets, D.G., Yarber, K.F., Nelson, S.M., Woo, J.H., Klimont, Z., 2004. A technology-based global inventory of black and organic carbon emissions from combustion. Journal of Geophysical Research 109 (D14203), 1-43.

Borken, J., Steller, H., Meretei, T., Vanhove, F., 2007. Global and country inventory of road passenger and freight transportation: Fuel consumption and emissions of air pollutants in 2000. Transportation Research Record, 2011, doi:10.3141/ 2011-14.

Borken, J., Steller, H., Meretei, T., Vanhove, F., 2008. Road transport's exhaust emissions in the year 2000 - country and gridwise. Meteorologische Zeitschrift (20/12/2006, under revision)

Bose, R.K., Nesamani, K.S., 2001. Urban Transport, Energy, and Environment: A Case Study of Delhi. PREPARED for the Pew Climate Centre, Delhi. Tata Energy Research Institute (TERI), New Delhi.

CPCB, 2000. Transport Fuel Quality for Year 2005. Central Pollution Control Board, Government of India, New Delhi, pp. 92-213.

CPCB, 2003. Parivesh: Transport Fuel Adulteration. Central Pollution Control Board, Government of India, New Delhi, pp. 1-9.

Faiz, A., Weaver, C.S., Walsh, M.P., 1996. Air Pollution From Motor Vehicles: Standards and Technologies for Controlling Emissions. The World Bank, Washington, D.C

Fulton, L., Eads, G., 2004. IEA/SMP model documentation and reference case projection. International Energy Agency/World Business Council for Sustainable Development. Available at: 〈http://www.wbcsd.org/web/publications/ mobility/smp-model-document.pdf $\rangle$.

Garg, A., Shukla, P.R., Kapshe, M., 2006. The sectoral trends of multigas emissions inventory of India. Atmospheric Environment 40, 4608-4620.

Gupta, 2001. Fuel Quality Initiatives- Indian Experience. Workshop on 'Fuel quality and Alternative Fuels'. Asian Development Bank, New Delhi 2-4 May 2001.

Gkatzoflias, D., Kouridis, C., Ntziachristos, L., Samaras, Z., 2007. COPERT 4 (Computer Programme to Calculate Emissions from Road Transport): User Manual Version 5. European Environment Agency, Copenhagen, Denmark.

HBEFA, 2004. Handbuch für Emissionsfaktoren des Strassenverkehrs (HBEFA Version 2.1). Umweltbundesamt Berlin, Umweltbundesamt, Wien, Bundesamt für Umwelt, Wald und Landschaft, Bern, and Infras AG, Bern, 2004. (CD-ROM, in German).

IEA, A., 2007. Energy Statistics of Non-OECD Countries, 2004-2005, 2007 edition OECD, Paris.
IFEU, 2004. Entwicklung eines Modells zur Berechnung der Luftschadstoffemissionen und des Kraftstoffverbrauchs von Verbrennungsmotoren in mobilen Geräten und Maschinen. Endbericht, UFOPLAN Nr. 29945 113, Heidelberg (in German).

IIASA, 2008. GAINS for India \& South Asia: BL India SNAP1 Categories. Available at: http://www.iiasa.ac.at/web-apps/apd/gains/〉, calculated 02042008

IMF (International Monetary Fund), 2008. World Economic Outlook Database April 2008 Edition. Available at: 〈http://www.imf.org/external/pubs/ft/weo/ 2008/01/weodata/index.aspx $\rangle$, accessed 05.05.2008.

IPCC (Inter-Governmental Panel on Climate Change), 1996. IPCC Good Practice Guidance and Uncertainty Management in National Greenhouse Gas Inventories. Cambridge University Press, New York.

Iyer, N.V., Badami, M.G., 2007. Two-wheeled motor vehicle technology in India: evolution prospects and issues. Energy Policy 35, 4319-4331.

Iyer, N.V., 2006. Vehicle Technology-Two and Three Wheelers in Asia: Current and Future Greenhouse Gas Emissions. Climate Change Mitigation in the Transport Sector Workshop. Asian Development Bank, Manila.

Kapoor, M., 2002. Vision 2020: transport. Planning Commission/Government of India, New Delhi, India.

Karim, M.M., 1999. Traffic pollution inventories and modelling in metropolitan Dhaka, Bangladesh. Transportation Research Part D 4, 291-312.

Kojima, M., Brandon, C., Shah, J., 2000. Improving Urban Air Quality in South Asia by Reducing Emissions from Two-Stroke Engine Vehicles. The World Bank, Washington, DC., USA.

Mashelkar, R.A., Biswas, D.K., Krishnan, N.R., Mathur, O.P., Natarajan, R., Niyati, K.P. Shukla, P.R., Singh, D.V., Singhal, S., 2002. Report of the Expert Committee on Auto Fuel Policy. Ministry of Petroleum and Natural Gas, Government of India, New Delhi.

MiEF, 2004. India's Initial National Communication to the United Nations Framework Convention on Climate Change. Ministry of Environment and Forests, Government of India, New Delhi, pp. 38-41.

MiPNG, 2004. Indian Petroleum and Natural Gas Statistics, 2002-03. Ministry of Petroleum and Natural Gas, Government of India, New Delhi.

Mittal, M.L., Sharma, C., 2003. Anthropogenic emissions from energy activities in India: generation and source characterization (Part-II.): emissions from vehicular transport in India.

Ntziachristos, L., Samaras, Z., 2000. COPERT III (Computer programme to calculate emissions from road transport): methodology and emission factors (Version 2.1). Technical Report No.49, European Environment Agency, Copenhagen, Denmark

Ohara, T., Akimoto, H., Kurokawa, J., Horii, N., Yamaji, K., Yan, X., Hayasaka, T., 2007. An Asian emission inventory of anthropogenic emission sources for the period 1980-2020. Atmospheric Chemistry and Physics 7, 6843-6902.

Olivier, J.G.J., Berdowski, J.J.M., Peters, J.A.H.W., Bakker, J., Visschedijk, A.J.H., Bloos J.P.J., 2002. Applications of EDGAR Emission Database for Global Atmospheric Research. ISBN: 905851077 8, Global Change NOP-NRP Report 410200051 RIVM rapport 773301001, 155 p.

Padam, S., Singh, S.K., 2001. Urbanization and Urban Transport in India: the sketch for a policy. Transport Asia Project Workshop, Pune, India, available at: 〈htpp://www.deas.harvard.edu/TransportAsia/workshop_papers/Padam-Singh. pdf $\rangle$

Parikh, S.K., Radhakrishna, R., 2005. India Development Report 2004-05. Oxford University Press, New Delhi, India.

Ramanathan, R., Parikh, J.K., 1999. Transport sector in India: an analysis in the context of sustainable development. Transport Policy 6 (1), 35-45.

RiTES, 1999. Comprehensive study of road transport flows in the country: Final report. RiTES/Government of India.

Shrestha, R.M., Malla, S., 1996. Air pollution from energy use in a developing country city: the case of Kathmandu Valley, Nepal. Energy 21 (9), 785-794.

SIAM, 2006. The Indian automobile industry: statistical profile 2005-2006. Society of Indian Automobile Manufacturers, New Delhi, India. 
SIAM, 2008. Automobile domestic sales trends. Available at: <http://www. siamindia.com/scripts/domestic-sales-trend.aspx $\rangle$, accessed 12.05.2008.

Singh, S.K., 2006. Future mobility in India: implications for energy demand and $\mathrm{CO}_{2}$ emission. Transport Policy 13, 398-412.

Singh, A., Gangopadhyay, S., Nanda, P.K., Bhattacharya, S., Sharma, C., Bhan, C. 2008. Trends of greenhouse gas emissions from the road transport sector in India. Science of the Total Environment 390, 124-131.

TERI, 2001. Urban Transport and Potential Mitigation Options for Delhi: Final Project Report. Tata Energy Research Institute, New Delhi, India.

TRW/MoSRTH, 2005. Road Transport Yearbook 2003-2004. Transport Research Wing, Ministry of Shipping Road Transport and Highways, Government of India, New Delhi.

University of California Riverside, 2004. Pune vehicle activity study (9 March 2003). Available at: 〈http://www.unipune.ernet.in/dept/env/pei/puneivem.pdf $\rangle$.
US-EPA, 2002. Technical guidance on the use of MOBILE6 for emission inventory preparation. US Environmental Protection Agency, Office of Air and Radiation, Office of Transportation and Air Quality, Washington, DC. Available at: <http:// www.epa.gov/oms/models/mobile6/420r04013.pdf $>$.

Van Aardenne, J., Dentener, F., Olivier, J.G.J., Peters, J.A.H.W., 2005. The EDGAR 3.2 Fast Track 2000 dataset (32FT2000). Netherlands Environmental Assessment Agency, Rijswijk. Available at: 〈http://www.rivm.nl/edgar/model/v32ft2000ed $\operatorname{gar} />$.

Zachariadis, T. Ntziachristos, L., Samaras, Z., 2001. The effect of age and technological change on motor vehicle emissions. Transportation Research Part D 6, 221-227.

Zachariadis, T., Samaras, Z., Zierock, K.H., 1995. Dynamic modelling of vehicle populations: An engineering approach for emissions calculations. Technological Forecasting and Social Change 50,135-149. 